\title{
PTGS2 gene polymorphism $-765 G>C$ is associated with coronary artery disease: a meta-analysis
}

\author{
C.-L. Xuan' ${ }^{1}$ W. Yan' ${ }^{1}$ L. Xuan² and R.-H. Xu' ${ }^{1}$ \\ ${ }^{1}$ Department of Cardiac Surgery, Second Hospital of Jilin University, \\ Jilin University, Changchun, Jilin, China \\ ${ }^{2}$ Norman Bethune Medical College, Jilin University, Changchun, Jilin, China \\ Corresponding author: R.-H. Xu \\ E-mail: xu6mouse@163.com
}

Genet. Mol. Res. 13 (1): 1491-1496 (2014)

Received June 29, 2013

Accepted October 23, 2013

Published January 14, 2014

DOI http://dx.doi.org/10.4238/2014.January.14.10

\begin{abstract}
Previous studies focusing on the association of PTGS2 polymorphism $-765 \mathrm{G}>\mathrm{C}$ with coronary artery disease (CAD) have failed to reach the same conclusion. In the present study, we performed a meta-analysis to systematically summarize the possible association between PTGS2 polymorphism $-765 \mathrm{G}>\mathrm{C}$ and the risk of CAD. We conducted a search of case-control studies on the associations of PTGS2 with susceptibility to CAD in PubMed, EMBASE, and Chinese National Knowledge Infrastructure databases. Data from eligible studies were extracted for meta-analysis. CAD risk associated with PTGS2 -765G $>\mathrm{C}$ was estimated by pooled odds ratios (ORs) and $95 \%$ confidence intervals $(95 \% \mathrm{CI})$ with the RevMan 5.2 software. Eleven independent case-control studies on PTGS2 $-765 \mathrm{G}>\mathrm{C}$ were included in our meta-analysis. Our results showed that $P T G S 2-765 \mathrm{G}>\mathrm{C}$ was associated with a decreased risk of $\mathrm{CAD}(\mathrm{OR}=0.66,95 \% \mathrm{CI}=0.56-0.79 ; \mathrm{P}<0.001)$. This meta-analysis suggests that $P T G S 2-765 \mathrm{G}>\mathrm{C}$ is associated with a decreased risk of CAD.
\end{abstract}

Key words: PTGS2; Coronary artery disease; Meta-analysis 


\section{INTRODUCTION}

Coronary artery disease (CAD) is a complex multifactorial and polygenic disorder in which multiple environmental and genetic factors are simultaneously involved (Xie et al., 2011). Therefore, the identification of genetic determinants associated with CAD risk has tremendous importance from a public health perspective. Recently, a number of case-control studies have suggested that $-765 \mathrm{G}>\mathrm{C}$ polymorphism in the PTGS2 gene is associated with the risk of CAD (Cipollone et al., 2004, 2009; Hegener et al., 2006; Lee et al., 2008; Szczeklik et al., 2008; Kohsaka et al., 2008; Huuskonen et al., 2008; Li et al., 2009; Rudock et al., 2009; Sanak et al., 2010; McGettigan et al., 2011; Ol et al., 2011).

Cyclooxygenase (COX) is the key enzyme for the production of prostaglandins (PGs) from free arachidonic acid and two isoforms of COX have been identified. COX-1 is constitutively expressed in most normal tissues and is considered to be a housekeeping enzyme that is responsible for various physiological functions. In contrast, COX-2 is rarely expressed in normal tissues, but is rapidly induced in response to cytokines, growth factors and tumor promoters (Dubois et al., 1998; Smith et al., 2000). COX-2-derived prostaglandins participate in angiogenesis, inhibition of apoptosis, and immune response suppression, which have been associated with cardiovascular disease. COX-2 has been found to be upregulated in atherosclerotic plaques (Kuge et al., 2007), and the polymorphisms of its gene, designated as PTGS2, have previously been associated with ischemic heart disease and risk of stroke (Colaizzo et al., 2006; Orbe et al., 2006). However, several studies indicated that there may be no association between PTGS2 polymorphism and CAD (Hegener et al., 2006; Lee et al., 2008). Therefore, we systematically reviewed the data published to date on the relationship between PTGS2 polymorphism and CAD risk and quantitatively summarized the available evidence by performing a formal meta-analysis.

\section{MATERIAL AND METHODS}

\section{Search strategy, eligibility criteria, and data extraction}

A systematic review of original articles, reviews, and meta-analyses analyzing the association between PTGS2 locus polymorphisms and CAD risk was performed by two independent investigators. The search was carried out in the PubMed, Embase, and Chinese National Knowledge Infrastructure (CNKI) databases with the following search terms: "PTGS2 or COX-2 or rs 20417" AND "CAD" or "Myocardial infarction" or "Coronary artery disease" or "Acute coronary syndrome" or "ACS". Disagreements were resolved by iteration, discussion, and consensus. To unravel potential systematic biases, a third investigator performed a concordance study by independently reviewing all eligible studies; complete concordance $(100 \%)$ was reached for all variables assessed.

Publication date and publication language were not restricted in our search. Reference lists were examined manually to further identify potentially relevant studies. The following data were extracted from eligible studies: the first author's last name, year of publication, country of origin, the numbers of genotyped cases and controls, and genotyping methods. All studies matching the inclusion criteria were retrieved for further examination and data extraction. All investigators had received training in literature search, statistics, and evidence-based medicine. 


\section{Statistical analysis}

Meta-analysis was performed by using the RevMan 5.2 software provided by the Cochrane Collaboration. We directly used Q-test and $\mathrm{I}^{2}$ test to examine the heterogeneity between each study. In the heterogeneity test, $\mathrm{P}>0.05$, we selected the Fixed Effect Mode1 to merge OR. To test the publication bias, we used the RevMan 5.2 statistical software to make the funnel plot. The statistical significance of the pooled OR was determined with the $\mathrm{Z}$ test, and a $\mathrm{P}<0.05$ was considered to be significant.

\section{RESULTS}

\section{Study characteristics}

A total of 386 articles were retrieved after first search in the databases above. After our selection, 11 case-control studies fulfilled the inclusion criteria. The qualities of the studies were considered to be acceptable for our meta-analysis. Characteristics of studies included are summarized in Table 1. A total of 11 studies involving 22,584 subjects were ultimately analyzed in our meta-analysis. In these 11 studies, four genotyping methods were employed including TaqMan, Illumina Human550 BeadChips, PCR-RFLP and sequencing. The genotype distribution in the controls was in agreement with Hardy-Weinberg equilibrium (HWE) in all of the studies included.

\begin{tabular}{|c|c|c|c|c|c|c|c|c|}
\hline \multirow[t]{2}{*}{ Author } & \multirow[t]{2}{*}{ Year } & \multirow[t]{2}{*}{ Country } & \multirow[t]{2}{*}{ Genotyping methods } & \multirow[t]{2}{*}{ No. (Cases/controls) } & \multicolumn{2}{|c|}{ Genotype case $(\%)$} & \multicolumn{2}{|c|}{ Genotype control (\%) } \\
\hline & & & & & GG & $\mathrm{GC}+\mathrm{CC}$ & GG & $\mathrm{GC}+\mathrm{CC}$ \\
\hline Cipollone & 2004 & Italy & $\mathrm{N} / \mathrm{A}$ & $864 / 864$ & 700 & 164 & 441 & 423 \\
\hline Hegener & 2006 & USA & Taqman & $600 / 600$ & 474 & 126 & 463 & 137 \\
\hline Kohsaka & $2008 \mathrm{a}$ & Turkey & Chips & $1153 / 8814$ & 825 & 329 & 6391 & 2423 \\
\hline Kohsaka & $2008 b$ & Australia & Taqman & $334 / 3128$ & 160 & 174 & 1411 & 1717 \\
\hline Lee & $2008 \mathrm{a}$ & USA & Taqman & $776 / 607$ & 546 & 230 & 425 & 182 \\
\hline Lee & $2008 b$ & USA & Taqman & $224 / 255$ & 113 & 111 & 111 & 144 \\
\hline McGettigan & 2011 & Canada & Taqman & $460 / 640$ & 336 & 124 & 478 & 162 \\
\hline Morgan & 2007 & USA & Sequenom MALDI-TOF & $811 / 650$ & 576 & 217 & 447 & 195 \\
\hline $\mathrm{Ol}$ & 2011 & USA & PCR-RFLP & $118 / 80$ & 48 & 70 & 27 & 53 \\
\hline Xie & 2009 & China & PCR-RFLP & $356 / 350$ & 234 & 122 & 245 & 105 \\
\hline Xie & 2011 & China & PCR-RFLP & $430 / 470$ & 364 & 66 & 368 & 102 \\
\hline
\end{tabular}

\section{Meta-analysis}

The association between PTGS2 $-765 \mathrm{G}>\mathrm{C}$ and susceptibility to CAD was analyzed in 11 independent studies. Results of the meta-analysis are shown in Figure 1. The Q-test showed no significant heterogeneity $\left(\mathrm{P}=0.68, \mathrm{I}^{2}=0 \%\right)$. Therefore, the fixed-effects model was used to analyze the association. In our analysis, significant differences were observed for the comparison of $\mathrm{GG} v s \mathrm{GC}+\mathrm{CC}(\mathrm{OR}=0.66,95 \% \mathrm{CI}=0.56-0.79 ; \mathrm{P}<0.0001$; Figure 1$)$.

\section{Publication bias}

The funnel plot and Egger test were performed to assess the publication bias of the literature. Symmetrical funnel plots were obtained in the SNP tested. The Egger test further confirmed the absence of publication bias in this meta-analysis $(\mathrm{P}>0.05)$ (Figure 2). 


\begin{tabular}{|c|c|c|c|c|c|c|}
\hline Study or Subqroup & loq[Odds Ratio] & SE & Weight & $\begin{array}{l}\text { Odds Ratio } \\
\text { IV, Fixed, } 95 \% \mathrm{Cl}\end{array}$ & \multicolumn{2}{|c|}{$\begin{array}{c}\text { Odds Ratio } \\
\text { IV, Fixed, } 95 \% \mathrm{Cl}\end{array}$} \\
\hline Cipollone 2004 & -0.62 & 0.13 & $45.4 \%$ & $0.54[0.42,0.69]$ & 맘 & \\
\hline Hegener 2006 & -0.07 & 0.46 & $3.6 \%$ & $0.93[0.38,2.30]$ & & \\
\hline Kohsaka 2008a & 0.02 & 0.54 & $2.6 \%$ & $1.02[0.35,2.94]$ & & \\
\hline Kohsaka 2008b & -0.05 & 0.47 & $3.5 \%$ & $0.95[0.38,2.39]$ & & - \\
\hline Lee $2008 a$ & -0.01 & 0.52 & $2.8 \%$ & $0.99[0.36,2.74]$ & & \\
\hline Lee 2008b & -0.12 & 0.41 & $4.6 \%$ & $0.89[0.40,1.98]$ & & - \\
\hline McGettigan 2011 & 0.04 & 0.58 & $2.3 \%$ & $1.04[0.33,3.24]$ & & \\
\hline Morgan 2007 & -0.07 & 0.45 & $3.8 \%$ & $0.93[0.39,2.25]$ & & \\
\hline 이 2011 & -0.13 & 0.45 & $3.8 \%$ & $0.88[0.36,2.12]$ & & - \\
\hline Xie 2009 & -0.47 & 0.19 & $21.3 \%$ & $0.63[0.43,0.91]$ & $=-$ & \\
\hline Xie 2011 & -0.19 & 0.35 & $6.3 \%$ & $0.83[0.42,1.64]$ & & \\
\hline Total $(95 \% \mathrm{Cl})$ & & & $100.0 \%$ & $0.66[0.56,0.79]$ & $\bullet$ & \\
\hline \multicolumn{4}{|c|}{$\begin{array}{l}\text { Heterogeneity: } \mathrm{Chi}^{2}=7.52, \mathrm{df}=10(\mathrm{P}=0.68) ; \mathrm{I}^{2}=0 \% \\
\text { Test for overall effect: } Z=4.68(\mathrm{P}<0.00001)\end{array}$} & & $\begin{array}{ll}0.01 & 0.1 \\
\text { Fayors } & \end{array}$ & $1 \begin{array}{cc}10 & 100\end{array}$ \\
\hline
\end{tabular}

Figure 1. Forest plot of MI risk associated with COX-2. The squares and horizontal lines correspond to the studyspecific OR and $95 \% \mathrm{CI}$, respectively. The area of the squares reflects the study-specific weight. The diamond represents the pooled results of OR and $95 \% \mathrm{CI}$. In this analysis, fixed-effects model was used.

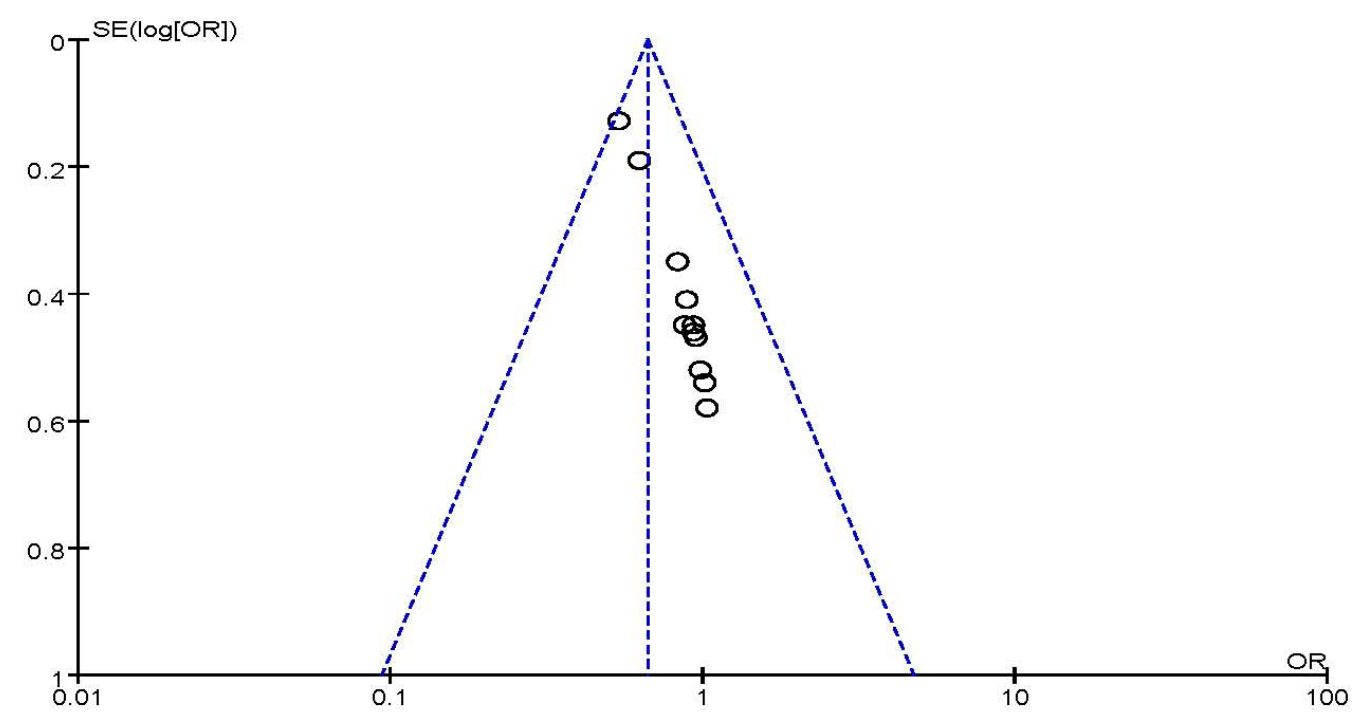

Figure 2. Begg's funnel plot for publication bias test. Each circle denotes an independent study for the indicated association. $\log [\mathrm{OR}]$, natural logarithm of OR. Horizontal line stands for mean effect size.

\section{Sensitivity analysis}

We deleted one single study from the overall pooled analysis each time to check the influence of the removed data set on the overall ORs. The pooled ORs and 95\%CIs were not significantly altered when any part of the study was omitted, which indicated that any single study had little impact on the overall ORs. 


\section{DISCUSSION}

We investigated the influence of the PTGS2 polymorphism on the risk of CAD by conducting a meta-analysis. We found the $-765 \mathrm{G}>\mathrm{C}$ polymorphism in the promoter region of the PTGS2 gene was associated with a significantly decreased risk of CAD. These findings suggest that the PTGS2 $-765 \mathrm{G}>\mathrm{C}$ polymorphism could be used as a marker for genetic susceptibility to CAD.

A - $765 \mathrm{G}>\mathrm{C}$ polymorphism in the promoter region of the COX-2 gene disrupts the Sp1 binding site (Papafili et al., 2002), which may alter the susceptibility to develop CAD. A previous study has shown that the $-765 \mathrm{C}$ allele may provide protective effects against myocardial infarction (Cipollone et al., 2004). The C allele may also be associated with lower levels of inflammatory markers such as C-reactive protein and interleukin-6 in cardio/cerebrovascular and hypercholesterolemic patients (Sowers et al., 2005). In contrast to these prior data, Hegener et al. (2006) found no evidence for an association of the polymorphism with risk of incident CAD (Delgado et al., 2004). Furthermore, Kohsaka et al. (2008) have recently reported that the -765C allele is in fact a risk factor for incident stroke in African-Americans (Bresalier et al., 2005).

In this meta-analysis, a total of 11 case-control studies were analyzed to provide a comprehensive assessment of the association between PTGS2 -765G $>$ C polymorphism and CAD. All the studies checked genotypes for quality control. Genotype distribution of controls in all studies was consistent with HWE. In addition, exploring heterogeneity is one of the important goals of a meta-analysis. In the present study no significant heterogeneity was found between the studies included. Sensitivity analysis also showed that omission of any single study did not have significant impact on the combined ORs. Furthermore, a funnel plot did not reveal obvious asymmetry, and the Egger test further indicated no considerable publication bias in this metaanalysis. This made the results of this meta-study more reliable to some extent.

There are some limitations in the present meta-analysis. In the studies included, the genotyping methods used were not the same. Besides, other clinical factors such as age, gender and different chemotherapies in each study might have led to bias. Determining whether or not these factors influence the results of this meta-analysis would need further investigation.

In conclusion, our study suggests that $P T G S 2-765 \mathrm{G}>\mathrm{C}$ is associated with a significantly decreased risk of CAD. Larger well-designed epidemiological studies with ethnically diverse populations and functional evaluations are warranted to confirm our findings.

\section{REFERENCES}

Bresalier RS, Sandler RS, Quan H, Bolognese JA, et al. (2005). Cardiovascular events associated with rofecoxib in a colorectal adenoma chemoprevention trial. N. Engl. J. Med. 352: 1092-1102.

Cipollone F (2009). Cox-2 polymorphisms and cardiovascular disease: elucidating the hidden side of the disease. Atherosclerosis 207: 348-349.

Cipollone F, Toniato E, Martinotti S, Fazia M, et al. (2004). A polymorphism in the cyclooxygenase 2 gene as an inherited protective factor against myocardial infarction and stroke. JAMA 291: 2221-2228.

Colaizzo D, Fofi L, Tiscia G, Guglielmi R, et al. (2006). The COX-2 G/C -765 polymorphism may modulate the occurrence of cerebrovascular ischemia. Blood Coagul. Fibrinolysis 17: 93-96.

Delgado RM, Nawar MA, Zewail AM, Kar B, et al. (2004). Cyclooxygenase-2 inhibitor treatment improves left ventricular function and mortality in a murine model of doxorubicin-induced heart failure. Circulation 109: 1428-1433.

Dubois RN, Abramson SB, Crofford L, Gupta RA, et al. (1998). Cyclooxygenase in biology and disease. FASEB J. 12: 1063-1073. 
Hegener HH, Diehl KA, Kurth T, Gaziano JM, et al. (2006). Polymorphisms of prostaglandin-endoperoxide synthase 2 gene, and prostaglandin-E receptor 2 gene, C-reactive protein concentrations and risk of atherothrombosis: a nested case-control approach. J. Thromb. Haemost. 4: 1718-1722.

Huuskonen KH, Kunnas TA, Tanner MM, Mikkelsson J, et al. (2008). COX-2 gene promoter polymorphism and coronary artery disease in middle-aged men: the Helsinki sudden death study. Mediators Inflamm. 2008: 289453.

Kohsaka S, Volcik KA, Folsom AR, Wu KK, et al. (2008). Increased risk of incident stroke associated with the cyclooxygenase 2 (COX-2) G-765C polymorphism in African-Americans: the Atherosclerosis Risk in Communities Study. Atherosclerosis 196: 926-930.

Kuge Y, Takai N, Ishino S, Temma T, et al. (2007). Distribution profiles of membrane Type-1 matrix metalloproteinase (MT1-MMP), matrix metalloproteinase-2 (MMP-2) and cyclooxygenase-2 (COX-2) in rabbit atherosclerosis: comparison with plaque instability analysis. Biol. Pharm. Bull. 30: 1634-1640.

Lee CR, North KE, Bray MS, Couper DJ, et al. (2008). Cyclooxygenase polymorphisms and risk of cardiovascular events: the Atherosclerosis Risk in Communities (ARIC) study. Clin. Pharmacol. Ther. 83: 52-60.

Li W, Xu J, Wang X, Chen J, et al. (2009). Cyclooxygenase-2 (COX-2) G-765C is a protective factor for coronary artery disease but not for ischemic stroke: a meta-analysis. Atherosclerosis 207: 492-495.

McGettigan P, Lincz LF, Attia J, McElduff P, et al. (2011). The risk of coronary thrombosis with cyclo-oxygenase-2 inhibitors does not vary with polymorphisms in two regions of the cyclo-oxygenase-2 gene. Br. J. Clin. Pharmacol. 72: 707-714.

Morgan TM, Krumholz HM, Lifton RP and Spertus JA.(2007) Nonvalidation of reported genetic risk factors for acute coronary syndrome in a large-scale replication study. JAMA 297:1551-1561.

Ol KK, Agachan B, Gormus U, Toptas B, et al. (2011). Cox-2 gene polymorphism and IL-6 levels in coronary artery disease. Genet. Mol. Res. 10: 810-816.

Orbe J, Beloqui O, Rodriguez JA, Belzunce MS, et al. (2006). Protective effect of the G-765C COX-2 polymorphism on subclinical atherosclerosis and inflammatory markers in asymptomatic subjects with cardiovascular risk factors. Clin. Chim. Acta 368: 138-143.

Papafili A, Hill MR, Brull DJ, McAnulty RJ, et al. (2002). Common promoter variant in cyclooxygenase-2 represses gene expression: evidence of role in acute-phase inflammatory response. Arterioscler. Thromb. Vasc. Biol. 22: 1631-1636.

Rudock ME, Liu Y, Ziegler JT, Allen SG, et al. (2009). Association of polymorphisms in cyclooxygenase (COX)-2 with coronary and carotid calcium in the Diabetes Heart Study. Atherosclerosis 203: 459-465.

Sanak M, Plutecka H, Szczeklik W, Piwowarska W, et al. (2010). Functional promoter polymorphism of cyclooxygenase-2 modulates the inflammatory response in stable coronary heart disease. Pol. Arch. Med. Wewn. 120: 82-88.

Smith WL, DeWitt DL and Garavito RM (2000). Cyclooxygenases: structural, cellular, and molecular biology. Annu. Rev. Biochem. 69: 145-182.

Sowers JR, White WB, Pitt B, Whelton A, et al. (2005). The effects of cyclooxygenase-2 inhibitors and nonsteroidal antiinflammatory therapy on 24-hour blood pressure in patients with hypertension, osteoarthritis, and type 2 diabetes mellitus. Arch. Intern. Med. 165: 161-168.

Szczeklik W, Sanak M, Rostoff P, Piwowarska W, et al. (2008). Common polymorphisms of cyclooxygenase-2 and prostaglandin E2 receptor and increased risk for acute coronary syndrome in coronary artery disease. Thromb. Haemost. 100: 893-898.

Xie X, Ma YT, Fu ZY, Yang YN, et al. (2009) Association of polymorphisms of PTGS2 and CYP8A1 with myocardial infarction. Clin. Chem. Lab. Med. 47:347-352.

Xie X, Ma YT, Yang YN, Fu ZY, et al. (2011). Interaction between COX-2 G-765C and smoking in relation to coronary artery disease in a Chinese Uighur population. Clin. Chem. Lab. Med. 49: 55-60. 